\title{
Relationship of Physical Activity to Self-Care Agency and Physical Condition Among Older Adults in a Rural Area
}

\author{
Junko Yoshimura,* Chika Tanimura,* Hiromi Matsumoto, $\dagger$ Yasuko Tokushima, $₫$ Kazuoki Inoue,§ Daeho Park\| \\ and Hiroshi Hagino $₫$ \\ *Department of Adult and Elderly Nursing, School of Health Science, Faculty of Medicine, Tottori University, Yonago 683-8503, Japan, \\ †Department of Physical Therapy, Faculty of Rehabilitation, Kawasaki University of Medical Welfare, Kurashiki 701-0193, Japan, \\ $\$$ Department of Nursing Care Environment and Mental Health, School of Health Science, Faculty of Medicine, Tottori University, \\ Yonago 683-8503, Japan, §Department of Community-based Family Medicine, Faculty of Medicine, Tottori University, Yonago 683- \\ 8503, Japan, \|Daisen Clinic, Daisen-cho, 689-3314, Japan, and $\mid$ Department of Fundamental Nursing, School of Health Science, \\ Faculty of Medicine, Tottori University, Yonago 683-8503, Japan
}

\section{ABSTRACT}

Background Maintaining physical activity is important for older adults. "Self-care agency" is the ability to perform self-care, which is defined as people following their own will, managing themselves, and maintaining activities. We investigated the relationship among physical activity and self-care agency, demographic factors and physical condition in older adults.

Methods Self-care agency was assessed by using the Self-Care Agency Questionnaire developed for Japanese patients with chronic diseases. Among 175 older adults aged 65 years or older living in a rural area, responses from 83 who performed physical activities were analyzed. Correspondence analysis was conducted to characterize demographic factors and self-care agency.

Results A higher proportion of women than men were engaged in physical activity. Irrespective of age and sex, many of the participants performed stretching exercises, walking, radio exercises, TV exercises, and participated in community circles. Participants who engaged in physical activities had significantly higher selfcare agency scores than inactive participants. Among the active participants, the self-care agency score was significantly higher for women than men $(P=.04)$ and was also significantly higher for participants aged $\geq 75$ years compared to those aged $<75$ years. Individuals with a high self-care agency tended to participate in local programs and perform brief physical activities at home.

Conclusion Physically active older adults demonstrated high self-care agency. Their activities were easily carried out in their daily lives, with activities varying by age and sex. Support from community health experts is needed to promote suitable physical activity among older adults tailored for age and sex, especially among older adults who have low self-care agency.

Key words locomotion; older adults; physical activity; self-care agency
Exercise has a positive effect on maintaining good health, and regular exercise is the most significant contributor to improving the quality of life in older adults. ${ }^{1}$ Several reports advocate the need for physical activity to maintain health, with physical activity encompassing the range of activities required for daily tasks as well as with exercise. ${ }^{2-4}$

According to the World Health Organization, "Physical activity includes exercise as well as other activities which involve bodily movement and are done as part of playing, working, active transportation, house chores and recreational activities. Increasing physical activity is a societal, not just an individual problem. Therefore, it demands a population-based, multisectoral, multi-disciplinary, and culturally relevant approach."4

Although the importance of physical activity is well known, engaging in physical activity is often more difficult for older adults due to pain or decreased range of motion caused by musculoskeletal diseases, increased risk of falls, and a tendency to a lower quality of life (QOL). ${ }^{5,6}$ The increased family burden of caring for older adults with fractures caused by falls or musculoskeletal diseases is becoming a significant social and medical problem. ${ }^{7}$

Various initiatives providing exercise programs for older adults that can be performed and continued daily have been implemented previously. ${ }^{8-11}$ However, these programs are often discontinued due to losing interest, being too busy, or due to age-related problems such as decreased motor functions or diseases that

Corresponding author: Junko Yoshimura jnn.yosimura@tottori-u.ac.jp

Received 2020 August 19

Accepted 2020 December 3

Online published 2021 January 6

Abbreviations: GLFS-5, 5-question Geriatric Locomotive Function Scale; LS, locomotive syndrome; QOL, quality of life; SCAQ, Self-Care Agency Questionnaire; VAS, visual analogue scale 
impair movement. ${ }^{12}$ These programs face the additional challenges of possible lack of facilities in rural areas or issues regarding accessibility ${ }^{13}$ and climate $^{14}$ affecting existing outdoor and indoor exercise facilities.

To provide effective exercise programs for older adults in a local community, appropriate activities should be selected, and the program should be developed by taking into consideration the concept of health, age/sex, physical strength, and the daily activities of participants. $^{15,16}$

Recommendation by healthcare professionals alone does not increase participation in physical activity. Self-care is also required, which is defined as acting according to one's own will, managing oneself, and maintaining activities. The ability to perform self-care has been designated as "self-care agency," which is an acquired capability influenced by age, gender, development, life experiences, health, social and cultural influences, and other resources, including available time. ${ }^{17}$ When providing exercise programs for older adults, selfcare agency should be assessed, and activities should match each participant's lifestyle. ${ }^{18}$ However, to date, no research exists on the relationship between physical activity and self-care agency among older adults.

To obtain insights into promotion of physical activity and exercise for older adults, the actual physical activities performed in a specific community should be clarified, as well as the relationship with self-care agency. Physical factors influencing the continuation of activities should also be evaluated.

This cross-sectional study was conducted as part of the Good Ageing and Intervention Against Nursing Care and Activity decline (GAINA) study, a joint project between Tottori University Faculty of Medicine and Hino town. ${ }^{19,20}$

This study aimed to identify the relationships among physical condition, self-care agency, and activities based on an analysis of comments collected from older adults about physical activity to obtain suggestions for increasing awareness of physical activity among older adults.

\section{SUBJECTS AND METHODS}

The GAINA study was performed in Hino town, a rural area in Tottori prefecture where winter snowfall is heavy. It is sparsely populated (3,278 residents), with a high proportion of residents aged $\geq 65$ years $(47.0 \%$ classified as aged in 2015). Among the 1,450 persons who were living in Hino town and who were targeted to undergo sponsored health checkups conducted by Hino town for adults aged $\geq 40$ years, 273 persons actually took the health checkup. This study's inclusion criteria were persons who (i) had the ability to perform physical function tests and (ii) had an adequate cognitive function to answer the questionnaire. Individuals receiving nursing care were excluded from this study. After screening, the current study included 223 participants who provided informed consent. Participants with missing data and those under 65 years of age were excluded from the analysis. A final 175 participants were included in the analysis for this study. The participant flow diagram is presented in Fig. 1. The 83 participants who provided comments on physical activity were designated as the physically active group.

\section{Data collection}

The survey was conducted between May and June 2014, and data were collected through a questionnaire that included the following scales.

\section{Physical activity}

The questionnaire was a free-response descriptive survey, and participants were asked to provide free-text comments about the physical activities they performed for health maintenance.

\section{Demographic profile}

Data were collected on the demographic profile, including age, sex, family members, and employment status. Because medical expenses and the need for nursing care are increased among persons $\geq 75$ years old, persons $<75$ years old are classified as the younger-old aged in Japan, while those $\geq 75$ years old are the old-old aged (Health Business Guidelines Based on Characteristics of Elderly Persons). ${ }^{21}$ Participants were classified using the same age groups $(<75$ years or $\geq 75$ years) in this study.

\section{Physical condition}

(i) Locomotive syndrome

In 2007, the Japanese Orthopaedic Association proposed the concept of locomotive syndrome (LS), which was defined as an increased risk of requiring support/primary nursing care due to a motor disorder. ${ }^{22}$ The Ministry of Health, Labour and Welfare in Japan subsequently raised awareness of LS in its Health Japan 21 program. ${ }^{23}$ The 5-question Geriatric Locomotive Function Scale (GLFS-5) was used to assess LS. This is a self-administered questionnaire with 5 items covering issues from pain to quality of life. Items are graded on a 5-point scale (0 to 4), and the scores are summed to obtain a total score from 0 (no impairment) to 20 (severe impairment). ${ }^{24}$ Participants were classified into a nonLS group or an LS group using 6 points as the cutoff value. 


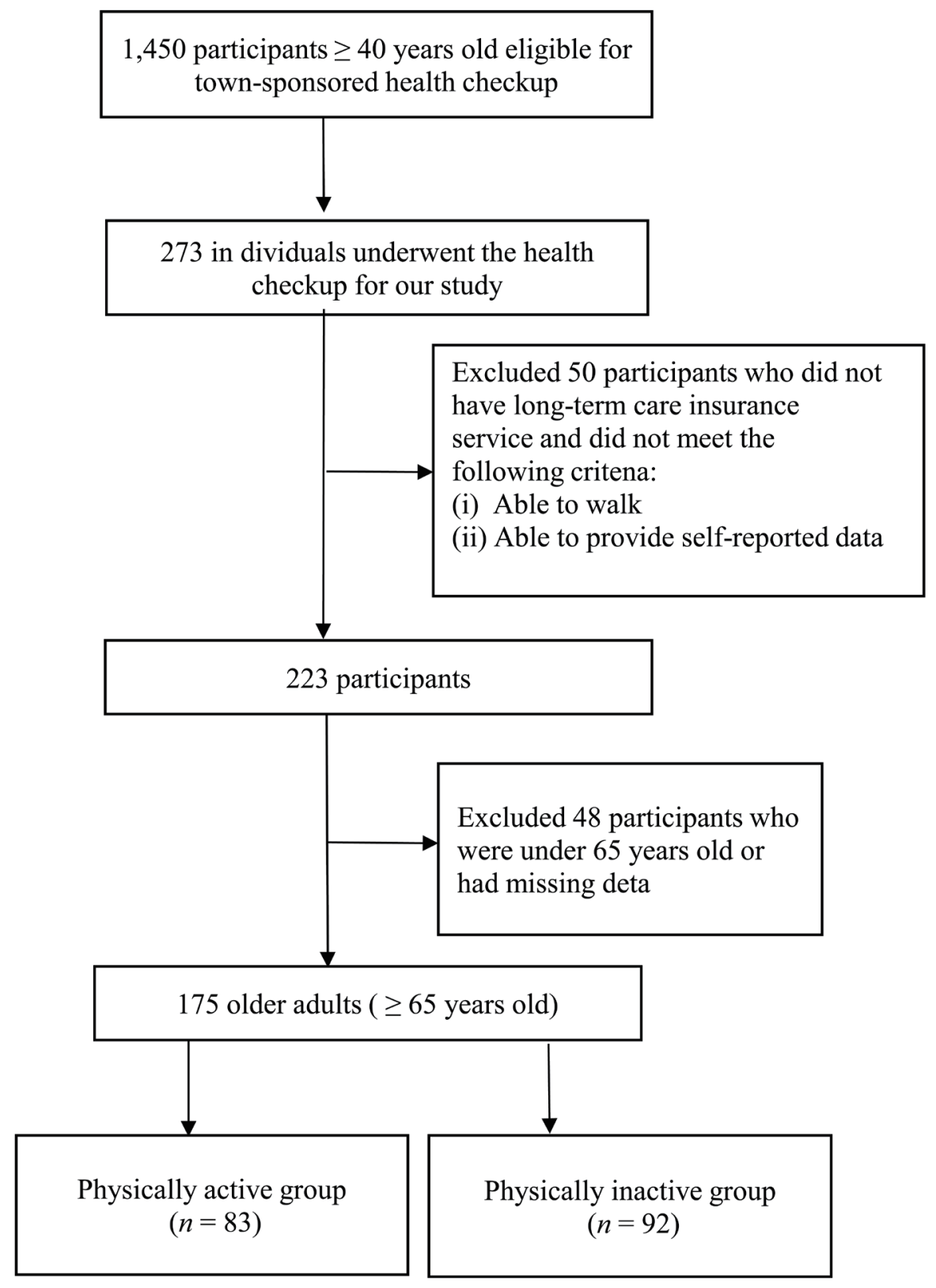

Fig. 1. Flow chart of participants.

(ii) Pain in the legs and lower back

Participants were asked, "Do you currently have pain in the legs or the lower back?" and were asked to record their pain on a $100-\mathrm{mm}$ visual analogue scale, with the "severest pain" ever experienced on the right end of the scale. The Japanese Society of Palliative Medicine pain classification was used to assign the participants to 4 groups: $0 \mathrm{~mm}$ : "no pain," $\geq 10 \mathrm{~mm}$ to $<40 \mathrm{~mm}$ : "mild pain," $\geq 40 \mathrm{~mm}$ to $<70 \mathrm{~mm}$ : "moderate pain," and $\geq 70$ $\mathrm{mm}$ to $100 \mathrm{~mm}$ : "severe pain."

\section{Self-care agency}

Questionnaires to measure self-care agency have been developed around the world. ${ }^{25-27}$

However, self-care agency is an acquired competence that is sensitive to life experiences and social and cultural influences. Self-care agency was assessed by using the Self-Care Agency Questionnaire (SCAQ) developed for Japanese patients with chronic diseases. The SCAQ was developed to reflect the characteristics and socio-cultural background of Japanese patients with chronic diseases and has been validated. ${ }^{28,} 29$ 
The questionnaire consists of 29 items in four subscales. The four subscales of self-care agency used in this study were as follows:

The subscale "ability to concentrate one's attention on self-care" was rephrased as "interest in health management" (7 items). The subscale "ability to perform self-care operations" was rephrased as "acquisition and maintenance of health management methods" (10 items). The subscale "ability to adjust one's own physical condition based on personal weaknesses" was rephrased as "adjustment of physical condition" (7 items). The subscale "ability to receive valid support" was rephrased as "obtaining effective support" (5 items). ${ }^{28}$

Each question was answered by selecting one of 5 options: "1: no," "2: probably no," "3: cannot decide," "4: probably yes" and "5: yes." A higher score indicates greater self-care agency, with the maximum total score being $145(35,50,35$, and 25 for the respective subscales). ${ }^{29}$

\section{Ethical considerations}

An informed consent form was sent to the participants in advance, and the questionnaires were collected soon after completion. This study was performed according to the Declaration of Helsinki and was approved by the institutional review board of Tottori University Faculty of Medicine (Approval No. 2354).

\section{Statistical analysis}

\section{Analysis of physical activity}

Free-text comments may contain different strings or words with the same or similar meanings. Text analysis can efficiently categorize similar strings or words from large amounts of data. The smallest unit of a string of letters that has a meaning is called a morpheme. The process of dividing a sentence into words and adding parts of speech and other relevant information is called morphological analysis.

Results of morphological analysis for "physical activity" were categorized by incidence using automated coding and then were classified manually according to the coding rules. Manual classification was conducted because this study was performed in Japanese participants, and each language has unique elements of style, grammar, and expression. ${ }^{30}$

Morphemes related to physical activity (exercise/ daily activities) were targeted. For example, the "walking" category contained the morphemes "walk" (verb), "a walk" (noun), "walking," "to walk" and "go for a walk." Comments such as "walking while playing ground golf" (modified golf similar to mini-golf) and "walking in the pool" were manually transferred from the morpheme "walk" to separate categories of "ground golf" and "swimming."

IBM SPSS Text Analytics for Surveys for Japanese Authorized User Ver. 4 was employed for the text analysis.

\section{Analysis of relationships among self-care agency and physical activity/demographic profile/physical condition}

Correspondence analysis is a technique for displaying the rows and columns of a data matrix (primarily, a twoway contingency table) as points in dual low-dimensional vector spaces. ${ }^{31}$ The method is conceptually similar to principal component analysis but applies to categorical rather than continuous data. It is like quantitation method III, which groups categorical data with similar cases and/or variables and allows visual presentation of the position of each variable. Before applying the correspondence analysis, a basic analysis contingency table (cross-tabulation) is created to determine whether there are any characteristics. Correspondence analysis visualizes the positional relationship of such characteristics. ${ }^{32}$

Correspondence analysis was used in this study because it can convert the results of cross-tabulation into scatter plots to help visualize the relationships between variables. Among the items investigated in this study, a cross summary table was made of (i) age and sex group rows $\times$ physical activity columns and (ii) SCAQ group rows $\times$ physical activity columns. Relationships were assessed as the distances between each row and column in a 2-dimensional figure.

The variables (physical activities) located at the origin point $(0,0)$ represent those performed by the majority of subjects, while fewer people are involved as the points become more distant from the origin. In addition, as physical activities (column) and (i) the age and sex group (row) or (ii) the SCAQ group (row) become closer in the figure, they are more closely related.

To assess self-care agency, the mean value was calculated for each of the 4 subscales, and then cluster analysis was performed to group the characteristics of the participants.

Results are presented as the mean \pm standard deviation or as the number (percentage). The independent $t$-test was used to examine the relationship between demographic factors and self-care agency, and the level of significance was set at $P<0.05$. IBM SPSS Statistics Version 24 was employed for these analyses.

\section{RESULTS \\ Demographic profile}

Sufficient data were obtained for 175 participants over 65 years old, and a detailed analysis was performed on 
Table 1. Baseline characteristics of the participants by sex

\begin{tabular}{|c|c|c|c|}
\hline & $\begin{array}{c}\text { Total } \\
(n=175)\end{array}$ & $\begin{array}{c}\text { Men } \\
(n=65)\end{array}$ & $\begin{array}{l}\text { Women } \\
(n=110)\end{array}$ \\
\hline Age (years) & $75.7( \pm 6.8)$ & $75.9( \pm 6.8)$ & $75.5( \pm 6.8)$ \\
\hline Age (range) & $(65-97)$ & $(65-97)$ & $(65-91)$ \\
\hline $65-74$ & $77(44 \%)$ & $27(35 \%)$ & $50(65 \%)$ \\
\hline$\geq 75$ & $98(56 \%)$ & $38(39 \%)$ & $60(61 \%)$ \\
\hline \multicolumn{4}{|l|}{ Family structure } \\
\hline Living alone & $39(22 \%)$ & $7(18 \%)$ & $32(82 \%)$ \\
\hline Two people & $75(43 \%)$ & $29(39 \%)$ & $46(61 \%)$ \\
\hline Three or more & $61(35 \%)$ & $29(48 \%)$ & $32(52 \%)$ \\
\hline \multicolumn{4}{|l|}{ Working } \\
\hline No & $69(39 \%)$ & $20(29 \%)$ & $49(71 \%)$ \\
\hline Yes & $106(61 \%)$ & $45(42 \%)$ & $61(58 \%)$ \\
\hline Farmer & $86(81 \%)$ & $36(42 \%)$ & $50(58 \%)$ \\
\hline Others & $20(19 \%)$ & $9(45 \%)$ & $11(55 \%)$ \\
\hline \multicolumn{4}{|l|}{ LS } \\
\hline No & $138(79 \%)$ & $55(40 \%)$ & $83(60 \%)$ \\
\hline Yes & $37(21 \%)$ & $10(27 \%)$ & $27(73 \%)$ \\
\hline \multicolumn{4}{|c|}{ Pain in legs and/or lower back (VAS: mm) } \\
\hline None & $56(32 \%)$ & $20(36 \%)$ & $36(64 \%)$ \\
\hline Mild & $67(38 \%)$ & $28(42 \%)$ & $39(58 \%)$ \\
\hline Moderate & $41(24 \%)$ & $14(34 \%)$ & $27(66 \%)$ \\
\hline Severe & $11(6 \%)$ & $3(27 \%)$ & $8(73 \%)$ \\
\hline
\end{tabular}

Results are shown as the mean $( \pm \mathrm{SD})$ for continuous variables or the number $(\%)$ for categorical data. LS, locomotive syndrome (cutoff value $=6$ ); VAS, visual analogue scale (Japanese Society for Palliative Medicine).

83 participants providing descriptions of their physical activities. Table 1 shows the demographic profile of the 175 participants.

\section{Physical activity}

Table 2 provides information on physical activity. After excluding 5 participants who described non-physical activities (inactive group), 83 participants were assigned to the physically active group. A total of 120 comments on physical activity (multiple replies) were obtained. Of the 15 types of physical activity listed, 11 were related to "exercise" and 4 were "activities of daily living." Stretching exercises were most popular (27 participants), followed by walking (21 participants), and radio/television (TV) exercises (21 participants). "Activities of daily living" included farming/gardening (6 participants), daily activities, outings, and dog walking (3 participants each).

\section{Self-care agency}

Among the 175 participants, the mean total score for the SCAQ was $125.1 \pm 16.3$ (range: $65-145$ ) points. The score was $129.1 \pm 14.0$ for women and $118.9 \pm 18.2$ for men, being significantly higher for women $(P=.02)$.

The mean score was 119.5 for men aged $<75$ years and 129.2 for men aged $\geq 75$ years, while the corresponding mean scores for women were 128.1 and 134.9, respectively. The mean score for the subscale "interest in health management" was $33.0 \pm 2.74(23-35)$, while the mean score was $41.9 \pm 7.26(22-50)$ for "acquisition and maintenance of health management methods," 30.6 \pm 4.59 (11-33) for "adjustment of physical condition," and $19.6 \pm 4.54(5-25)$ for "obtaining effective support."

The mean self-care agency score was $130.1 \pm 13.0$ in the physically active group versus $120.8 \pm 17.8$ in the inactive group, being significantly higher in the former $(P=.003)$. In the physically active group, the self-care agency score was significantly higher for women 132 \pm 11.4 than men $123.1 \pm 15.2(P=.04)$ and was also 
Table 2. Physical activities of 83 participants classified by type, sex, age, locomotive syndrome, and severity of pain (multiple answers) $(n=83)$

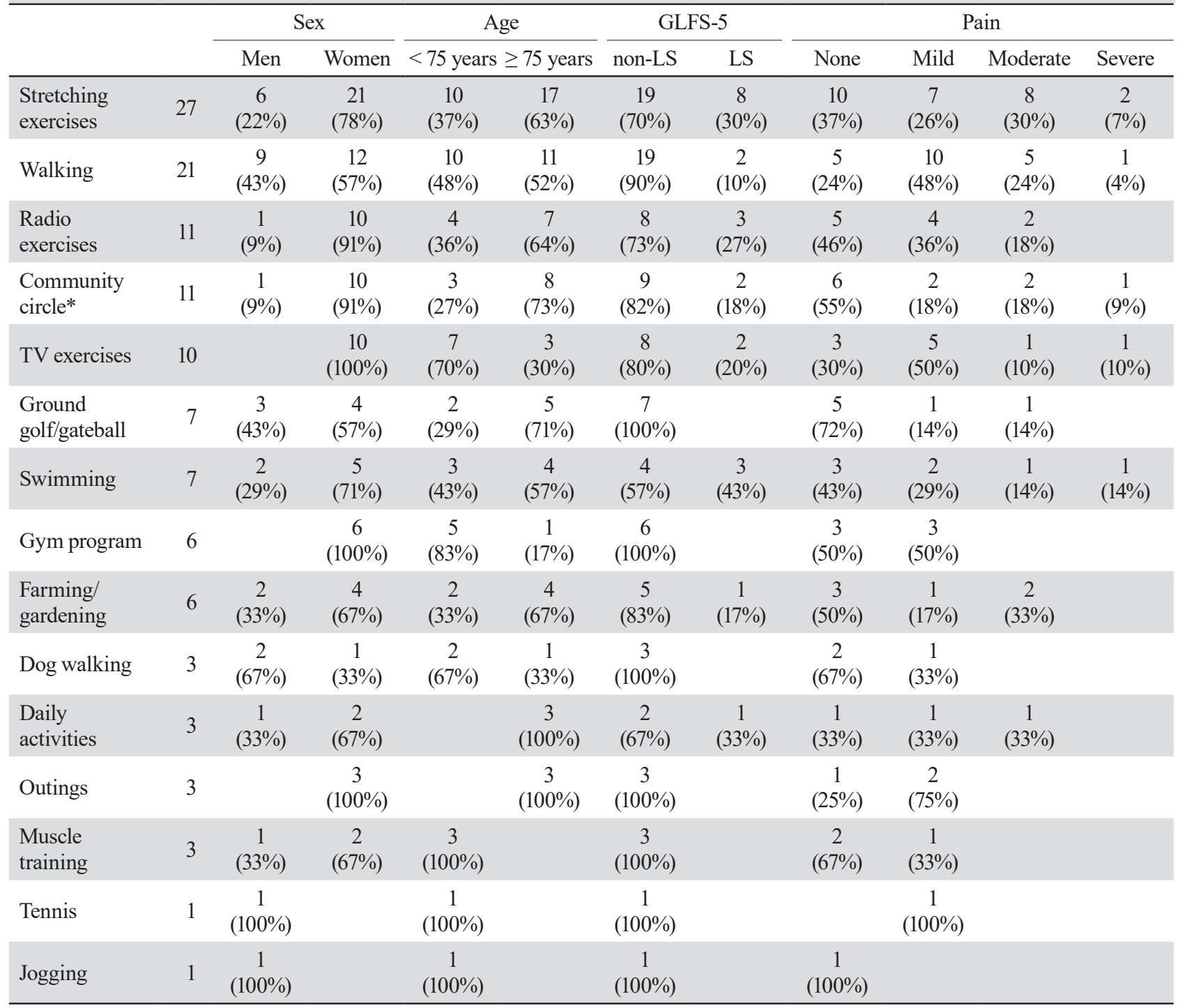

*Community circle: residents of a community performing exercises, etc. as a group. GLFS-5, The 5-question Geriatric Locomotive Function Scale (Japanese Orthopaedic Association); LS, locomotive syndrome; TV, television.

significantly higher for participants aged $\geq 75$ years compared with those aged $<75$ years. When classified by age and sex, the self-care agency score was significantly higher for women aged $\geq 75$ years than men aged $<75$ years. The score was 119.6, 129.2, 128.0, and 135.0 for men $<75$ years old, men $\geq 75$ years old, women $<$ 75 years old, and women $\geq 75$ years old, respectively. It was significantly higher for women $\geq 75$ years old than men $<75$ years old $(P<.01)$.

No significant differences were observed for the number of household members, GLFS-5 score, or pain.

\section{Relationship between physical activity and demo- graphic profile/physical condition}

Table 2 and Fig. 2 show data on the relationship between physical activity and demographic profile/physical condition. More women than men were engaged in physical activity, and most participated in group sports such as gym programs, community circle activities, ground golf, and gateball. Participants aged $\geq 75$ years engaged in more types of physical activity compared with those aged $<75$ years, including numerous types of "exercises." "Daily activities" such as farming/gardening, other daily activities, and outings were also common.

The participants were classified into 4 groups based on sex and age (men aged $<75$ years, men aged 


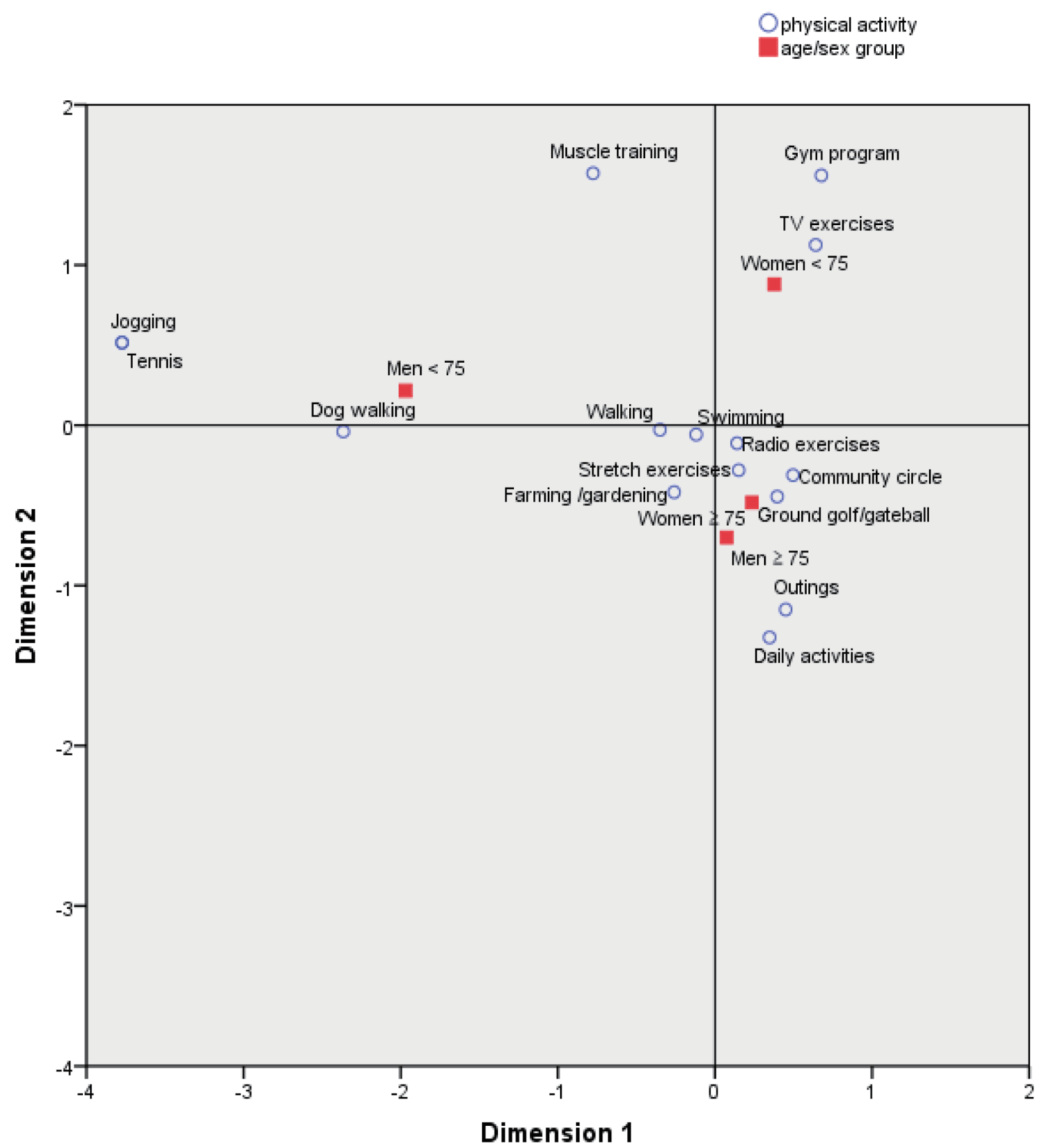

Fig. 2. Association of physical activities with each age/sex group. $\mathbf{a g e / s e x}$ group, $\circ$ physical activity. The variables (physical activities) located at the origin point $(0,0)$ represent those performed by the majority of subjects, while fewer people are involved as the points become more distant from the origin. As physical activities and the 4 age/sex groups become closer in the figure, they are more closely related. Age/sex groups $(n=83)$ : men $<75$ years old $(n=11)$; men $\geq 75$ years old $(n=14)$; women $<75$ years old $(n=24)$; women $\geq 75$ years old $(n=34)$. SCAQ, Self-Care Agency Questionnaire; TV, television.

$\geq 75$ years, women aged $<75$ years, and women aged $\geq$ 75 years), and a correspondence analysis was performed to examine relationships with physical activity in each group (Fig. 2). Correspondence analysis revealed that stretching exercises, radio exercises, walking, and swimming were clustered near the origin (0), indicating that many participants engaged in these activities irrespective of sex or age. In addition, tennis/jogging and dog walking were related with men aged $<75$ years, whereas ground golf and gateball were related with men aged $\geq 75$ years. Furthermore, radio exercises, ground golf, and community circle activities were related with women aged $\geq 75$ years, while gym programs and TV exercises were related with women aged $<75$ years. Older women preferred radio exercises and younger women preferred TV exercises, showing a difference in 


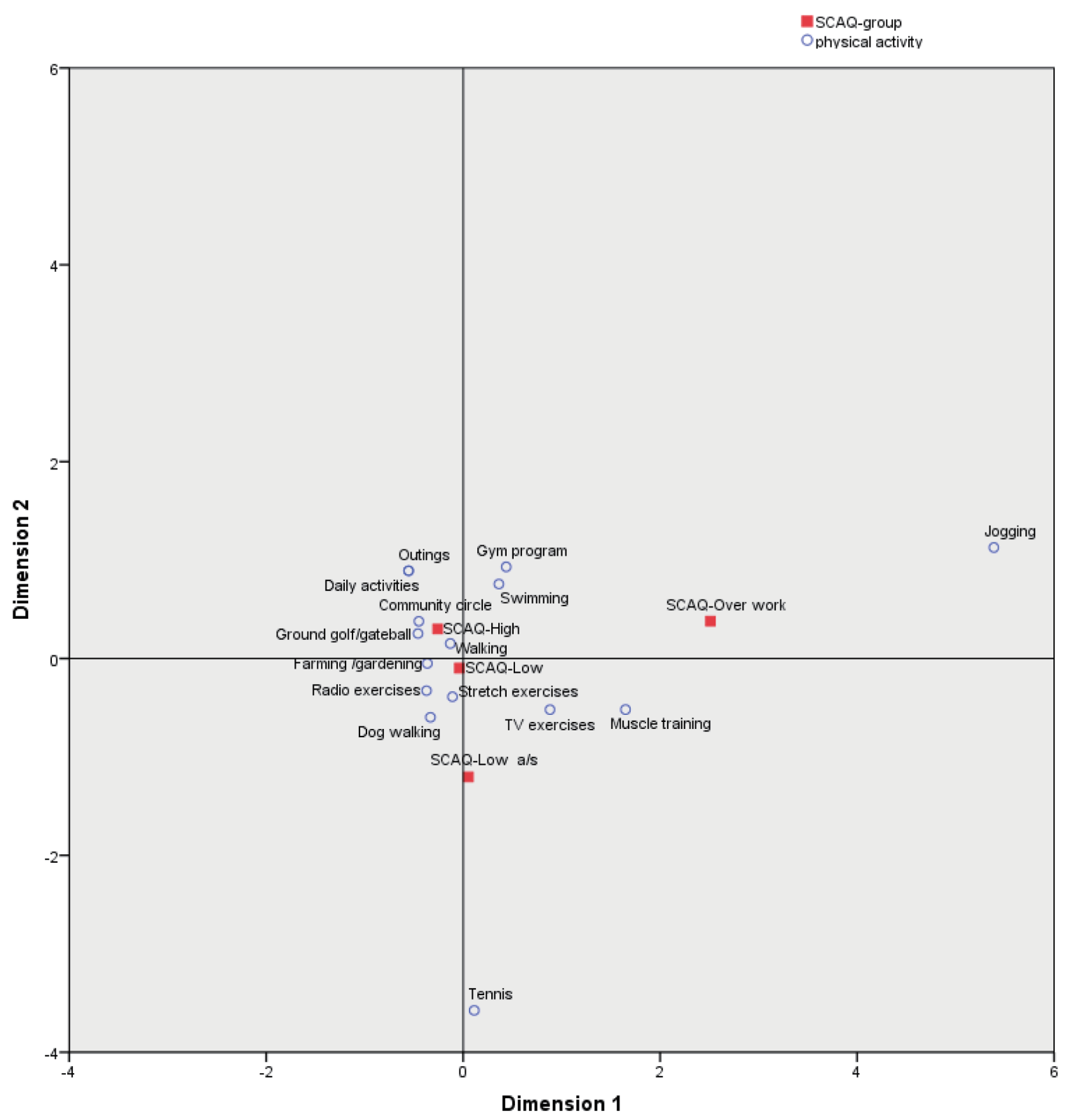

Fig. 3. Association of physical activities with each self-care agency subgroup. $\approx$ SCAQ group, o physical activity. The variables (physical activities) located at the origin point $(0,0)$ represent those performed by the majority of subjects, while fewer people are involved as the points become more distant from the origin. As physical activities and the 4 SCAQ groups become closer in the figure, they are more closely related. SCAQ groups $(n=83)$ : SCAQ-High $(n=20)$; SCAQ-Low $(n=12)$; SCAQ-Low a/s $(n=16)$; SCAQ-Over work $(n=35)$. SCAQ; Self-Care Agency Questionnaire, SCAQ-Low a/s, Self-Care Agency Questionnaire - Low "adjustment of physical condition" and "obtaining effective support." TV, television.

media preference for the same exercise program.

While fewer persons with LS engaged in physical activity, there were no differences in physical activity among the participants with no, mild, moderate, or severe pain. There were no significant differences in physical activity for age and sex.

\section{Relationship between physical activity and self- care agency}

Figure 3 displays the relationship between physical activity and self-care agency. Cluster analysis was conducted in the physically active group to classify the 4 characteristics of self-care agency. As a result, 20 participants with high scores for all of the 4 subscales were classified into the "SCAQ-High group." The 35 
participants with low only subscales on "adjustment of physical condition" were designated as the "SCAQOver work group." In addition, 16 participants with low scores for the 2 subscales "adjustment of physical condition" and "obtaining effective support" were assigned to the "SCAQ-Low a/s group," while 12 participants with low scores for all 4 subscales formed the "SCAQLow group." A correspondence analysis was conducted to examine the relationship between types of physical activity and these 4 SCAQ groups (Fig. 3). Walking and stretching exercises showed a relationship with all groups. The characteristic physical activity in the "SCAQ-High group" was participation in community circles, in the "SCAQ-Low group" it was jogging, tennis, or muscle training, and in the "SCAQ-Low a/s group" it was walking or stretching exercises.

\section{DISCUSSION}

This study demonstrated that "stretching exercises" and "walking" were popular among active older adults irrespective of sex or age. "Radio exercises," "TV exercises," and "community circle" were also popular among women. These activities are simple, involve familiar movements from daily life, and do not need special equipment, and so older adults can perform them as part of their daily routine. Many countries promote simple exercises such as the simplified tai chi established in 1956 in China ${ }^{33}$ or zumba. ${ }^{34}$ In Japan, "radio/TV exercises" are popular, and people are accustomed to them from childhood. Many women join a community circle because they can meet friends while performing simple and easy exercises. ${ }^{35}$ This study showed that many participants in community circles were living alone. Hence, these activities may enhance communication and socialization, ${ }^{36}$ as well as promoting exercise. Participants also performed exercise as part of their daily activities, such as "daily activities," "outings," and "farming/gardening," with the latter being one of the characteristic physical activities in the region studied.

Even older adults with impaired LS or with pain (mild to severe) were engaged in physical activities. Silva et al. ${ }^{37}$ discussed the effect of pain relief by water-based exercise and aquatic training ${ }^{38}$ in patients with knee osteoarthritis, and some of the participants performed walking in the swimming pool. It seems that older adults with pain performed "stretching exercises," "walking," "farming/gardening," and "daily activities" for self-management of health considering their impaired ability to exercise and pain.

The correspondence analysis showed that many older adults of both sexes undertook "walking" and "stretching" exercises, suggesting the popularity of exercises that are easily performed at home without cost. Women aged $<75$ years preferred "TV exercises" and "gym programs," whereas "jogging," "tennis," and "dog walking" were favored by men aged $<75$ years. "Muscle training" was popular among both men and women aged $<75$ years. Thus, older adults aged $<75$ years were capable of going out and engaged in more demanding physical activities to satisfy their need for exercise, even when transportation was required, or the activity was more difficult.

In addition, "radio exercises" were very popular among women. Ide defined the characteristics of people who adhere to exercise therapy as follows: membership of a gym or exercise circle, family cooperation, and walking exercise or indoor sports. ${ }^{18}$ The present study obtained similar results in terms of the types of physical activity. In Japan, the percentage of women in their $60 \mathrm{~s}$ and 70 s performing regular exercise is reported to be lower than that of $\operatorname{men}^{39}$; however, we found a higher percentage of women engaging in physical activity. Regional characteristics, family environment, agricultural work, and daily activities may influence physical activity among women. A suitable environment for physical activity, friendships, and appropriate activities according to age and sex may be important for older adults to continue physical activity.

The self-care agency score was significantly higher in the physically active group compared with the inactive group. Physically active older adults are considered to be health conscious and capable of obtaining the means and support for health management, suggesting the significance of enhancing self-care agency to promote physical activity among older adults in the community.

According to the correspondence analysis, "walking" and "stretching" exercises were preferred physical activities irrespective of differences in the self-care agency subscales. Walking and stretching do not need any equipment or sports facilities and can easily be performed by older adults.

When stratified by the self-care agency subscales, many participants in the SCAQ-High group were involved in "community circles."

Many participants in community circles live alone $^{36}$ and are often women over 75 years old. It is important to establish a process that allows communitydwelling older adults to develop self-management skills to maintain health and provide "community circles" they can enjoy with peers, especially since joining in public activities with friends provides stimulation and increases self-efficacy. ${ }^{40}$ Thus, older adults should be 
supported to continue participating in social activities while managing their physical condition.

Participants in the SCAQ-Low group selected relatively high-intensity sports such as "jogging," "tennis," and "muscle training." Self-care agency of the aged $\geq 75$ years is reported to be lower than that of aged $<75$ years. ${ }^{41}$ In this study, the self-care agency score was higher for participants aged $\geq 75$ years than those aged $<75$ years. Self-care agency is lower among younger persons than older adults, because it is necessary for health management and tends to be acquired in older age when physical function declines. Thus, the participants with low overall self-care agency aged $<75$ years presumably still had sufficient physical and motor function to select relatively intense activities.

Participants in the SCAQ-Low a/s group tended to engage in "stretching," "walking," and "TV/radio exercises." These activities can be done alone and are easily adopted by persons who do not want to burden others or are not good at group activities. Because adherence to exercise influences the ability to concentrate on selfcare and the ability to receive proper support, ${ }^{40}$ a system should be established to help older adults acquire a habit of physical activity. Our results suggest that ongoing participation in physical activity by older adults is more likely when their self-care agency is adequate for selfmanagement of health, suitable activities are provided according to sex or age, and a support system is established by family and local healthcare providers.

This study's findings provide suggestions for promoting suitable physical activity (depending on sex, age, and physical condition) among older adults who are not regularly engaged in physical activity. Support from friends, family, and healthcare providers is essential when proposing suitable physical activities for older adults, supporting improvement for low self-care agency, and promoting successful experiences and behavior modification through interactions in the community.

This study has several limitations. First, it was performed in a single community, so further investigation is required to confirm our findings. The participation rate for health checkups was low, limiting the number of eligible participants. The participants provided free-text comments about exercise, and we did not investigate whether those not providing comments were engaged in physical activity. It is also possible that participants might not have considered some "daily activities" to be physical activity and may only have listed "exercise." It is difficult to generalize the results because the number of samples was small, and the intensity, frequency, and duration of each type of physical activity were not analyzed because free-text comments were provided.
However, the findings provide some clues to encourage older adults who are not physically active to perform physical activity. Future research should assess the type of physical activity and the intensity, frequency, and duration of each activity.

In conclusion, this study investigated the relationship between physical activity and self-care agency among older adults living in a rural area and found that many men and women aged $\geq 75$ years participated in physical activities. Active older adults had significantly higher self-care agency scores than inactive participants, and self-care agency was higher among women than men. Our findings suggest that support from family members and healthcare providers is needed to promote suitable physical activity for older adults depending on their age and sex, especially those with low self-care agency.

Acknowledgments: We would like to thank the Hino town office for assistance with recruitment. The authors sincerely acknowledge the contributions of all GAINA study staff members. The authors also acknowledge Eri Kobayashi, Kyohei Nakata, Takeshi Sota, Taro Omori, Tomoyuki Makabe, Tetsuji Morita, Akihiro Matsuura, Naoyuki Nakaso, Nao Nakata, Tomoko Akita and Takuya Sugimura for technical support and assistance with data collection, and Ryoko Ikehara for secretarial assistance.

The authors declare no conflict of interest.

\section{REFERENCES}

1 Burbank PM, Riebe D, eds. Promoting exercise and behavior change in older adults: Interventions with the transtheoretical model. New York: Springer Publishing Co; 2001.

2 Hakim AA, Petrovitch H, Burchfiel CM, Ross GW, Rodriguez BL, White LR, et al. Effects of walking on mortality among nonsmoking retired men. N Engl J Med. 1998;338:94-9. DOI: 10.1056/NEJM199801083380204, PMID: 9420340

3 U.S. Department of Health and Human Services. Physical Activity and Health: A Report of the Surgeon General. Atlanta: U.S. Department of Health and Human Services, Centers for Disease Control and Prevention, National Center for Chronic Disease Prevention and Health Promotion; 1996.

4 World Health Organization [Internet]. Geneva: World Health Organization; c2019 [cited 2019 Aug 6]. Global Strategy on Diet, Physical Activity and Health: Physical Activity. Available from: https://www.who.int/dietphysicalactivity/pa/en/.

5 Matsumoto H, Nakaso N, Matsuura A, Akita T, Hagino H. Relationship between severity of locomotive syndrome and the incidence of falling, prevalence of low bone mass, and sarecopenia. Rigakuryohogaku. 2016;43:38-46. DOI: 10.15063/rigaku.11092 Japanese with English abstract.

6 Tanishima S, Hagino H, Matsumoto H, Tanimura C, Nagashima H. Association between sarcopenia and low back pain in local residents prospective cohort study from the GAINA study. BMC Musculoskelet Disord. 2017;18:452. DOI: 10.1186/s12891-017-1807-7, PMID: 29141602 
7 Ministry of Health. Labour and Welfare [Internet]. From Comprehensive Survey of Living Conditions, 2013: Graphical Review of Japanese Household [updated 2014 Jul 15, cited 2015 Jun 9]. Available from: http://www.mhlw.go.jp/toukei/ list/dl/20-21-h25.pdf. Japanese.

8 Kitabatake Y, Oida Y, Nakamura N, Morozumi K, Shiozawa $\mathrm{S}$, Sato $\mathrm{S}$, et al. The development of a rehabilitation program to reduce knee pain in the community-dwelling elderly: the relationship between the amount of physical exercise and the extent of reduction of knee pain. Tairyoku Kenkyu. 2006;104:6-16. DOI: 10.20793/tairyokukenkyu.104.0_6 Japanese with English abstract.

9 Kojima S, Tokumori K, Sakano N, Wang DH, Suzuki H, Ikeda S, et al. Factors contributing to enhancement of exercise habituation in exercise intervention for disability prevention in community-dwelling Japanese elderly. Taiikugaku Kenkyu. 2007;52:227-35. DOI: 10.5432/jjpehss.14 Japanese with English abstract.

10 Sakurai R, Fujiwara Y, Fukaya T, Saito K, Yasunaga M, Suzuki H, et al. [The influences of exercise fulfillment on mental and physical functions of targeted older adults and the effect of a physical exercise intervention]. Nihon Koshu Eisei Zasshi. 2012;59:743-54. Japanese with English abstract. PMID: 23240546

11 Sugimoto H, Demura S, Nagasawa Y, Shimomura M. Changes in the physical functions of pre-frail elderly women after participation in a 1-year preventative exercise program. Geriatr Gerontol Int. 2014;14:975-82. DOI: 10.1111/ggi.12198, PMID: 24299293

12 Yip YB, Sit JWH, Fung KKY, Wong DYS, Chong SYC, Chung LH, et al. Effects of a self-management arthritis programme with an added exercise component for osteoarthritic knee: randomized controlled trial. J Adv Nurs. 2007;59:20-8. DOI: 10.1111/j.1365-2648.2007.04292.x, PMID: 17559610

13 March L, Amatya B, Osborne RH, Brand C. Developing a minimum standard of care for treating people with osteoarthritis of the hip and knee. Best Pract Res Clin Rheumatol. 2010;24:121-45. DOI: 10.1016/j.berh.2009.10.002, PMID: 20129205

14 Ohsawa Y, Momiyama H, Ishikawa T, Tsugaruya M, Kondo M, Ashikaga A. [Basic research of physical, mental, living functions of home-dwelling elderly persons in winter]. Akita Rigaku Ryoho. 2005;13:11-4. Japanese.

15 McArthur D, Dumas A, Woodend K, Beach S, Stacey D. Factors influencing adherence to regular exercise in middleaged women: a qualitative study to inform clinical practice. BMC Womens Health. 2014;14:49. DOI: 10.1186/1472-687414-49, PMID: 24666887

16 Shishido Y, Ide R, Nikaido A, Nakano K, Yasumura S. [Relationships between participation of national-health-insurance members in a health education program and exercise habits, medical expenses and other related parameters]. Nihon Koshu Eisei Zasshi. 2003;50:571-82. Japanese with English abstract. PMID: 12934513

17 Orem DE. Nursing: Concepts of Practice. 6th ed. St Louis: Mosby; 2001.

18 Ide M, Shiiba M, Fukushima N, Takei R, Tajiri Y, Mimura $\mathrm{K}$, et al. [Persons adhering to exercise stratified by type of exercise, age, and common features]. (Fukuoka City Medical Association Center for Lifestyle-related Diseases). Practice. 2008;5:463-6. Japanese.
19 Matsumoto H, Hagino H, Sageshima H, Osaki M, Tanishima $\mathrm{S}$, Tanimura C. Diagnosis of knee osteoarthritis and gait variability increases risk of falling for osteoporotic older adults: the GAINA study. Osteoporos Sarcopenia. 2015;1:46-52. DOI: 10.1016/j.afos.2015.07.003

20 Matsumoto H, Hagino H, Osaki M, Tanishima S, Tanimura C, Matsuura A, et al. Gait variability analysed using an accelerometer is associated with locomotive syndrome among the general elderly population: the GAINA study. J Orthop Sci. 2016;21:354-60. DOI: 10.1016/j.jos.2016.02.003, PMID: 27020175

21 Ministry of Health. Labour and Welfare [Internet]. [Health Business Guidelines Based on Characteristics of Elderly Persons] [updated 2019 Apr, cited 2019 Aug 13]. Available from https://www.mhlw.go.jp/content/12401000/000557575.pdf. Japanese.

22 The Japanese Orthopaedic Association [Internet]. [Locomotive syndrome: A novel concept] [cited 2018 Sep 19]. Available from: https://www.joa.or.jp/public/locomo/index.html. Japanese.

23 Ministry of Health. Labour and Welfare [Internet]. Health Japan 21 (the second term): Basic direction for comprehensive implementation of national health promotion [updated 2012 Jul 10, cited 2018 Sep 20]. Available from http://www. mhlw.go.jp/file/06-Seisakujouhou-10900000-Kenkoukyoku/0000047330.pdf. Japanese.

24 Seichi A, Hoshino Y, Doi T, Akai M, Tobimatsu Y, Iwaya T. Development of a screening tool for risk of locomotive syndrome in the elderly: the 25-question Geriatric Locomotive Function Scale. J Orthop Sci. 2012;17:163-72. DOI: 10.1007/ s00776-011-0193-5, PMID: 22222445

25 .Gast HL, Denyes MJ, Campbell JC, Hartweg DL, SchottBaer D, Isenberg M. Self-care agency: conceptualizations and operationalizations. ANS Adv Nurs Sci. 1989;12:26-38. DOI: 10.1097/00012272-198910000-00006

26 Sousa VD, Zauszniewski JA, Bergquist-Beringer S, Musil CM, Neese JB, Jaber AF. Reliability, validity and factor structure of the Appraisal of Self-Care Agency Scale-Revised (ASAS-R). J Eval Clin Pract. 2010;16:1031-40. DOI: 10.1111/ j.1365-2753.2009.01242.x, PMID: 20626539

27 Söderhamn O, Evers G, Hamrin E. A Swedish version of the appraisal of Self-Care Agency (ASA) scale. Scand J Caring Sci. 1996;10:3-9. DOI: 10.1111/j.1471-6712.1996.tb00302.x, PMID: 8715780

28 Honjo K. Revision of the self-care agency questionnaire for patients with chronic illness. Journal of Japan Academy of Nursing Science. 2001;21:29-39. DOI: 10.5630/ jans1981.21.1 29 Japanese with English abstract.

29 Honjo K. [Self-care nursing]. Yokohama: LifeSupport Co; 2015. Japanese.

30 Uchida O, Kawashima A, Isozaki S. [Introduction to SPSS text analytics]. Tokyo: Ohmsha, Ltd.; 2014. Japanese.

31 Greenacre M. Correspondence analysis of raw data. Ecology. 2010;91:958-63. DOI: 10.1890/09-0239.1, PMID: 20462111

32 Uchida O. [Guide to multivariate analysis of survey results using SPSS]. 3rd ed. Tokyo: Tokyo Tosho Co., Ltd.; 2011. Japanese.

33 Lü J, Huang L, Wu X, Fu W, Liu Y. Effect of Tai Ji Quan training on self-reported sleep quality in elderly Chinese women with knee osteoarthritis: a randomized controlled trail. Sleep Med. 2017;33:70-5. DOI: 10.1016/ j.sleep.2016.12.024, PMID: 28449910 
34 Notarnicola A, Maccagnano G, Pesce V, Tafuri S, Leo N, Moretti B. Is the Zumba fitness responsible for low back pain? Musculoskelet Surg. 2015;99:211-6. DOI: 10.1007/s12306015-0370-3, PMID: 25904350

35 Shigematsu R, Nakanishi R, Saitoh M, Okura T, Nakagaichi M, Nakata Y, et al. [Reasons for older adults independently continuing exercise after a supervised Square-Stepping Exercise intervention]. Nihon Koshu Eisei Zasshi. 2011;58:229. Japanese with English abstract. PMID: 21409820

36 Tsujimoto H, Yamada K, Morioka I. Characteristics and changes in health status and life function among female participants of group exercise. Nippon Eiseigaku Zasshi (Japanese Journal of Hygiene). 2017;72:66-76. DOI: 10.1265/jjh.72.66, PMID: 28154364

37 Silva LE, Valim V, Pessanha APC, Oliveira LM, Myamoto S, Jones A, et al. Hydrotherapy versus conventional land-based exercise for the management of patients with osteoarthritis of the knee: a randomized clinical trial. Phys Ther. 2008;88:1221. DOI: 10.2522/ptj.20060040, PMID: 17986497
38 Waller B, Munukka M, Rantalainen T, Lammentausta E, Nieminen MT, Kiviranta I, et al. Effects of high intensity resistance aquatic training on body composition and walking speed in women with mild knee osteoarthritis: a 4-month RCT with 12-month follow-up. Osteoarthritis Cartilage. 2017;25:1238-46. DOI: 10.1016/j.joca.2017.02.800, PMID: 28263901

39 Ministry of Health. Labour and Welfare [Internet]. National Health and Nutrition Survey 2016, Section 3 [updated 2017 December, cited 2018 August 2]. Available from: https://www.mhlw.go.jp/content/000681180.pdf. Japanese.

40 Tanimura C, Matsumoto H, Tokushima Y, Yoshimura J, Tanishima S, Hagino H. Self-care agency, lifestyle, and physical condition predict future frailty in community-dwelling older people. Nurs Health Sci. 2018;20:31-8. DOI: 10.1111/ nhs.12376, PMID: 29115022

41 Dale B, Söderhamn U, Söderhamn O. Self-care ability among home-dwelling older people in rural areas in southern Norway. Scand J Caring Sci. 2012;26:113-22. DOI: 10.1111/j.14716712.2011.00917.x, PMID: 21883344 